\title{
Advantage of Kilner's Modification of Mouth Gag in Reference to Simple Technique Overcoming a Persistent Problem in Cleft Palate Repair
}

\author{
P. Varun Menon ${ }^{1}$
}

Received: 28 April 2016/ Accepted: 19 November 2016/Published online: 26 November 2016

(C) The Association of Oral and Maxillofacial Surgeons of India 2016

\section{To the Editor}

I read with great interest the article by Kotrashetti et al. [1] describing the use of a rubber dam to overcome the potential disadvantage of suture adherence during repair of palatal tissue especially mentioned to overcome the difficulty of suture getting tethered at various places of the instrument during cleft palate closure.

The authors may have find it useful with this usage of rubber dam application; but I tend to differ on this matter; as mentioned in literature the very purpose when Kilner added a spring coil around the top was to hold sutures in perfect order prior to tying, in keeping with his tidy surgery [2-4]. In 1962, Dingman and Grabb modified the open, C-shaped frame Dott-Kilner gag modified into a rectangular, closed frame [5].

So by covering up the spring coils as mentioned in the technical note the others are negating the above mentioned advantage which was incorporated to serve its purpose.

Meticulous surgical and suturing technique can very much overcome the difficulty of suture getting tethered at various places of the instrument during cleft palate closure or the surgeons can go ahead and use various other mouth gags that has been mentioned in literature [5]. With my limited experience I can very much say like in any surgery inorder to reduce the total operative time a systematic step by step approach is very much essential for the successful outcome and palate repair is no different. Utilising the kilner's modifications of the mouth gag to hold sutures in perfect order prior to tying also helps in achieving the above goal to an extent in cleft palate repair.

\section{References}

1. Kotrashetti SM, Dube G, Thakkar B et al (2016) Simple technique overcoming a persistent problem in cleft palate. J Maxillofac Oral Surg 15:558

2. Millard DR (1980) Anesthesia in clefts (gas, tubes and gags). Cleft craft. Little Brown, Boston, pp 147-148

3. Bodley P (1978) Development of anaesthesia for plastic surgery. J R Soc Med 71:839-843

4. Holdsworth W (1970) Cleft lip and palate, 4th edn. William Heinemann Medical Books, London

5. Ameer F, Singh AK, Kumar S (2014) The story of mouth gags. J Cleft Lip Palate Craniofac Anom 1:70-77
P. Varun Menon

varunmp@gmail.com

1 Department of Oral and Maxillofacial Surgery, Jubilee Mission Medical College and Research Institute, Thrissur, Kerala, India 